\title{
Los repositorios institucionales dentro de las estrategias de preservación de la información sobre patrimonio
}

Álvaro Rodríguez Miranda, José Manuel Valle Melón | Laboratorio de Documentación Geométrica del Patrimonio, Grupo de Investigación en Patrimonio Construido, Universidad del País Vasco

URL de la contribución <www.iaph.es/revistaph/index.php/revistaph/article/view/3950>

Los datos culturales, tanto brutos como elaborados, son fuente de conocimiento y riqueza, generan valores, asientan el conocimiento y permiten la dinamización de sectores como el cultural, el turístico y el educativo. La disponibilidad de información cultural permite el contraste de las fuentes, datos y procesos y posibilita que estos puedan ser reproducidos, corroborando o refutando hipótesis y generando nuevos conocimientos.

Consideramos, dentro del marco de la preservación patrimonial, el diseño y la implementación de estrategias para la preservación y la re-utilización de la información, en las que se deben satisfacer cinco condiciones (RODRÍGUEZ MIRANDA, 2014: 11): transcendencia, localización, lectura, comprensión y credibilidad.

Exponemos a continuación la estrategia desarrollada en el caso del Laboratorio de Documentación Geométrica del Patrimonio (Universidad del País Vasco, UPV/EHU), donde se realizan tanto actividades de formación e investigación en el ámbito académico, como de transferencia a través de proyectos de documentación de elementos patrimoniales a petición de terceros (generalmente, administraciones públicas). Desde el año 2012 (CASTRO MARTÍN; GARCÍA GÓMEZ; RODRÍGUEZ MIRANDA, 2012) se empezó a colaborar con la biblioteca de la universidad con el fin de disponer de un espacio en el repositorio institucional (ADDI) que permitiese garantizar la preservación y difusión de la información generada sobre elementos patrimoniales.

Un atractivo de los repositorios universitarios es que están directamente conectados a través de redes de ciencia abierta -como Recolecta-y agregadores culturales -como Hispana e incluso Europeana- (RODRÍGUEZ MIRANDA; VALLE MELÓN; PORCAL GONZALO, 2013).
Este hecho amplía de manera muy significativa las posibilidades de acceso a la información desde diferentes ámbitos.

En la actualidad, el Laboratorio dispone de más de un centenar de registros en ADDI que incluyen trabajos académicos, publicaciones científicas, informes de proyectos de investigación, aplicaciones informáticas de uso libre y proyectos de documentación de elementos patrimoniales. De estos últimos se incluye siempre, al menos, la memoria de actuación, lo que deja constancia del trabajo realizado (registros de información, procesos aplicados y productos generados) y, en los casos en los que no se infringen los derechos de explotación de terceros, también se incluyen diversos conjuntos de datos como colecciones fotográficas, modelos tridimensionales, planos, etc.

En nuestra experiencia de estos años, han sido numerosos los potenciales usuarios que se han puesto en contacto con el Laboratorio, tiempo después de una intervención, al respecto de trabajos realizados de cuya existencia se han enterado gracias a que el repositorio de la universidad informaba de ello. Como se ha comentado anteriormente, no siempre podemos proporcionar determinados tipos de datos, ya que los derechos de explotación siguen correspondiendo a las administraciones contratantes pero, cuando menos, se proporciona una vía de contacto entre los interesados y las citadas administraciones.

Lamentablemente, también ha sido frecuente que, una vez que el usuario se ha puesto en contacto con la administración, esta ya no dispusiera de los datos al no haber realizado ningún tipo de archivo ni acción de preservación y mantenimiento de la información. Sin embargo, 


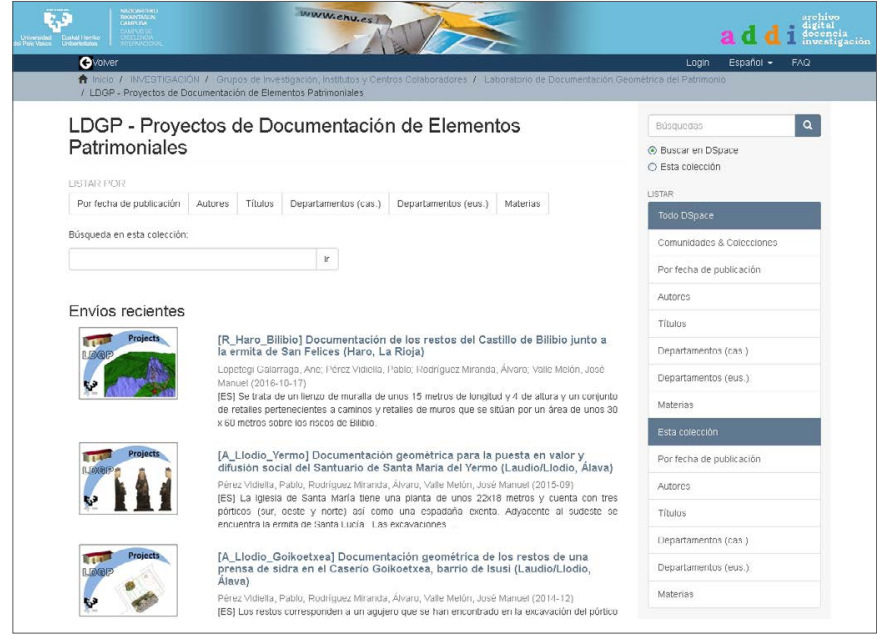

Informes de proyectos realizados por el Laboratorio de Documentación Geométrica del Patrimonio (https://addi.ehu.es/handle/10810/7029)

aún en estos casos se puede sacar alguna consecuencia positiva ya que al menos la pérdida de información no queda ignorada, lo que es un primer paso necesario para concienciar de la magnitud del problema y poder adoptar medidas para abordarlo.

Por otro lado, es evidente que cualquier acción de justificación, mantenimiento o mejora de las estrategias de preservación y difusión tiene que estar basada en datos objetivos que permitan evaluar la situación de partida y cuantificar los cambios generados. Por consiguiente, el control de uso de la información que se ofrece, así como la capacidad de dar respuesta a las necesidades de los usuarios que acceden a ella debe ser considerado por las organizaciones en todo momento.

A este respecto, la difusión a través de repositorios aporta cierto control sobre el número y la procedencia de los accesos a través de los contadores. Por supuesto, también, puede existir una retroalimentación directa de los usuarios; de hecho, más allá de los números generales que facilitan las estadísticas de uso generadas automáticamente, suelen ser estos porcentualmente pocos casos de comunicación directa los que proporcionan una mayor rentabilidad a la organización que difunde la información.
La publicación en repositorios institucionales, frente a hacerlo en redes sociales o repositorios comerciales, supone una serie de ventajas, como son: la trascendencia más allá de las personas, el acceso abierto sin contraprestación comercial, la indexación en agregadores -lo que permite la disponibilidad global desde el almacenamiento local-, la garantía de actualización de formatos y migración tecnológica o el compromiso institucional con la transcendencia.

Por ello, los repositorios institucionales son una alternativa no sólo a la difusión (con marcado carácter puntual) sino también para dotar de trascendencia en el tiempo y facilitar el acceso a la información patrimonial.

Para concluir nos gustaría indicar que, a pesar de que aún son muchos los aspectos que deben desarrollarse (tecnologías, estándares de documentación, formación, etc.), ya existen posibilidades viables que permiten implementar, al menos parcialmente, el acceso abierto a los datos, con el consiguiente beneficio tanto para las organizaciones como para el patrimonio y la sociedad.

\section{BIBLIOGRAFÍA}

- castro martín, P. DE; garcía gómez, C.; RODRÍGUEZ MIRANDA, Á. (2012) Gestión de datos de investigación en repositorios de acceso abierto: una visión panorámica y un caso práctico en la UPV/EHU. En La motricidad de los repositorios de acceso abierto. 5as jornadas OS-Repositorios. Bilbao (España). 23-25 Mayo 2012 <http:// hdl.handle.net/10810/13913> [Consulta: 14/07/2017]

- ROdRíguez MIRANDA, Á.; VALLE MELÓN, J. M.; PORCAL GONZALO, M.C. (2013) Enriching the content provided by cultural catalogues with data from institutional repositories. ISPRS Annals of the Photogrammetry, Remote Sensing and Spatial Information Sciences, II-5/W1, 2013, pp. 277-282 <doi:10.5194/isprsannals-II-5-W1-277-2013> <http:// hdl.handle.net/10810/10559> [Consulta: 14/07/2017]

- RODRÍGUEZ MIRANDA, Á. (2014) Documentación espacial del patrimonio: preservación de la información. Necesidades, posibilidades, estrategias y estándares. Tesis doctoral Universidad del País Vasco (UPV/EHU) <http://hdl. handle.net/10810/13617> [Consulta: 14/07/2017] 